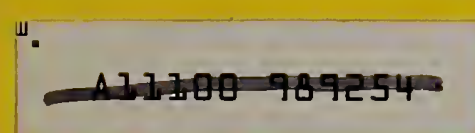

NBS

PUBLICATIONS
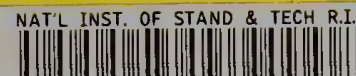

AL1105 156199

NBSIR 80-2060

\title{
Drafting Test Methods for Photovoltaic Systems
}

W. F. Lankford and H. A. Schafft

Electron Devices Division

Center for Electronics and

Electrical Engineering

National Bureau of Standards

U.S. Department of Commerce

Washington, DC 20234

June 1980

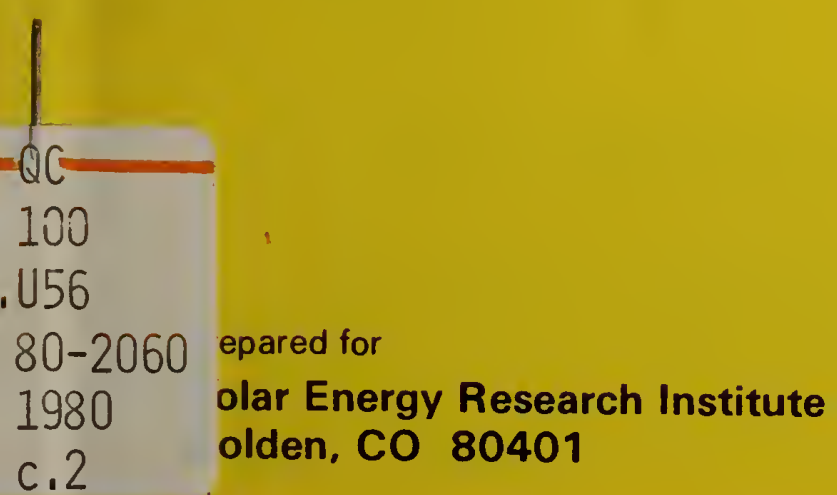



W. F. Lankford and H. A. Schafft

Electron Devices Division

Center for Electronics and

Electrical Engineering

National Bureau of Standards

U.S. Department of Commerce

Washington, DC 20234

June 1980

Prepared for

Solar Energy Research Institute

Golden, CO 80401

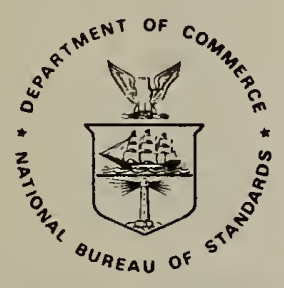

U.S. DEPARTMENT OF COMMERCE, Philip M. Klutznick, Secretary

Luther :4. Hodges, Jr., Deputy Secretary

Jordan J. Baruch, Assistant Secretary for Productivity. Technology, and Innovation

NATIONAL BUREAU OF STANDARDS, Ernest Ambler, Director 

Abstract . . . . . . . . . . . . . . . . . . . . .

1. Introduction . . . . . . . . . . . . . . . . . 1

2. Introduction of a Test Method Draft to a Standards-Writing

Committee - General Considerations . . . . . . . . . . . . . 4

3. Effectiveness Criteria for Test Method Standards . . . . . . . 5

3.1 Practicality and Economic Feasibility . . . . . . . . . . 5

3.2 Lack of Impedance of New Development . . . . . . . . . 5

3.3 Avoidance of Unfair Discrimination . . . . . . . . . . . 5

4. Preparatory Work for Writing and Introducing a Test Method . . . . 6

4.1 Background Information Search . . . . . . . . . . . 6

4.2 Appropriateness of Method . . . . . . . . . . . . . 6

4.3 Principles and Assumptions . . . . . . . . . . . . 8

4.4 Experimental Error Analysis ................. 8

4.5 Areas of Dispute ..................... 8

4.6 General Criteria ..................... . . . 9

4.7 Basic References ..................... . . 9

4.8 Intralaboratory study ..... . . . . . . . . . . . . 9

4.9 Interlaboratory Pilot study . . . . . . . . . . . . . 9

5. Procedure for the Preparation of A Preliminary Test Method Draft . 10

5.1 Title . . . . . . . . . . . . . . . 10

5.2 scope ......................... . . . . 10

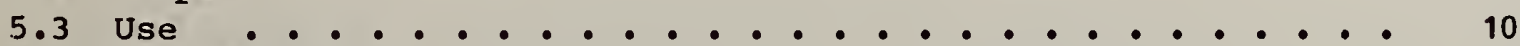

5.4 Significance ..................... . . . . . 10

5.5 Summary of Method ................... 11

5.6 Definition, Terminology, and Symbols ........... 11

5.7 Apparatus and Materials ............... . . 11

5.8 Safety .. . . . . . . . . . . . . . . . . . 11

5.9 Statistical Sampling and Measurement . . . . . . . . . 11

5.10 Procedure ......................... 12

5.10 .1 Error ....................... 12

5.10 .2 Checks ...................... 12

5.10 .3 Illustrations ................... 12

5.10 .4 Experience .................... 12

5.10 .5 Statistical Requirements . . . . . . . . . 12

5.10 .6 Repeated Measurements . . . . . . . . . . 12

5.10 .7 Interferences ................... 12

5.10 .8 Alternatives ................... 13

5.10 .9 SI Units ...................... 13

5.11 Calculations and Reporting. . . . . . . . . . . . . 13

5.12 List of References . . . . . . . . . . . . . . . . 13

5.13 Table of Contents ..................... 13

Acknowledgment . . . . . . . . . . . . . . . . . . . 14

References . . . . . . . . . . . . . . . . . . . . . 14 



\author{
Drafting Test Methods for Photovoltaic Systems* \\ William F. Lankford \\ and \\ Harry A. Schafft \\ Electron Devices Division \\ Center for Electronics and Electrical Engineering \\ National Bureau of Standards \\ Washington, DC 20234
}

\begin{abstract}
General guidance and a step-by-step procedure are provided as aids in the development of initial drafts of test methods for photovoltaic energy components and systems. It is intended that these drafts will be referred to the appropriate technical committees of organizations writing voluntary consensus standards. This approach is designed to facilitate the expeditious development of consensus test method standards for photovoltaic systems. The procedure is therefore designed to be compatible with the requirements of existing standards organizations.
\end{abstract}

Key Words: Consensus standards; measurement technology; photovoltaic energy conversion; photovoltaics; solar cells; test method preparation.

\title{
1. INTRODUCTION
}

The availability of photovoltaic (PV) energy conversion as a competitive source of power has been brought closer by improvements in terrestrial solar cell technology, significant reductions in the costs of PV systems and components, and an increasing awareness of the limitations and total costs of energy sources now being used.

A critical element in promoting an early and practical commercialization of PV energy conversion systems is a base of well-documented and widely accepted standards that are responsive to marketplace requirements. It is preferable that such a base of voluntary standards be developed by the consensus process to ensure acceptability. When the base is in place, it should facilitate reliable and consistent measurements. A recent review [1] has revealed, however, that there are few standards in place that are directly applicable to PV energy conversion systems and that, in fact, much work needs to be done to develop the standards base required for the full and effective use of PV systems on the scale that will make the PV option a viable one for the nation.

In the United States, the responsibility for developing standards for materials and products is assumed by consensus standards-writing organiza-

*This report was prepared under contract to the Solar Energy Research Institute (Subcontract No. XP-9-8028-1) in support of the Photovoltaic Performance Criteria and Test Standards Project. 
tions within professional societies, standards organizations, and trade associations. Such organizations typically form various technical comittees where the actual work of developing standards is carried out. The committees may include interested industry, user, government, and consumer representatives who prepare, revise, and approve the drafts of standards. The products of the technical committees are then subject to review through the ballot process and, when approved by the parent organization, may be submitted to the American National Standards Institute for adoption as American National Standards. Institutions such as the Institute of Electrical and Electronics Engineers (IEEE), the American Society for Testing and Materials (ASTM), and the Semiconductor Equipment and Materials Institute, Incorporated (SEMI) are representative of those concerned with standards for photovoltaic solar energy systems.

The development of a voluntary consensus standard is achieved most rapidly when there already exist one or more well-documented test methods commonly used in the field and the problem is to codify at least one of these methods and determine its precision in actual practice. It is often the case that little or no experimental development is required to achieve standardization of those methods. However, when significant research and evaluation work is necessary before an adequate initial draft of a test method can be prepared, the process of standards development by standards-writing organizations can be lengthened considerably. The Solar Energy Research Institute (SERI), as part of its response to the Photovoltaic Research, Development, and Demonstration Act of 1978 (PL-95-590), is managing a project to develop performance criteria and test methods for photovoltaic materials, components, subsystems, and systems. Promoting the expeditious development of test method standards is an important part of the project. SERI recognizes that significant preparatory work may indeed be needed to provide a foundation for important PV test methods and that this situation can cause significant delays in the development of the needed standards base. SERI, therefore, is interested in supporting, where appropriate, both the research and evaluation needed for the development of test methods, and the detailed preparation of initial drafts of such test methods in a form suitable for introduction to appropriate standards-writing organizations at a point where the consensus process can most effectively take over.

This report is directed to those involved in the development of these test methods and the preparation of initial test method drafts. These two activities, for a given test method, are regarded here as one unified effort. Sections 2 and 3 provide general considerations designed to facilitate consistency in the generation of the initial drafts. Section 4 provides a framework for the accelerated development of test methods and, in particular, for the orderly introduction and transfer of the test method drafts to the technical committees of standards-writing organizations. Finally, section 5 gives the step-by-step procedure for preparing a test method. This procedure necessarily cannot be too specific, as it is intended to reflect the requirements of wost. of those organizations that appear likely to be the most involved in PV standards development [2-6]. The specific provisions, level of detail, and even the general approach varies considerably from one organization to another. The procedure has been carefully designed to conform with the instructions of the individual standards-writing organizations. 
Table 1 outlines the steps described in this report for preparing a test method draft and developing it into a standard. These steps are ones that the preparer of a test method will need to consider and follow, as appropriate and as SERI may direct.

It should be pointed out that while the focus of the report is on the expeditious development of standards for PV systems, the guidelines and recommendations given here serve equally for other technologies in a similar stage of development.

Table 1 - Steps for Preparer of Test Method Draft (with Sections Where These Steps are Discussed)

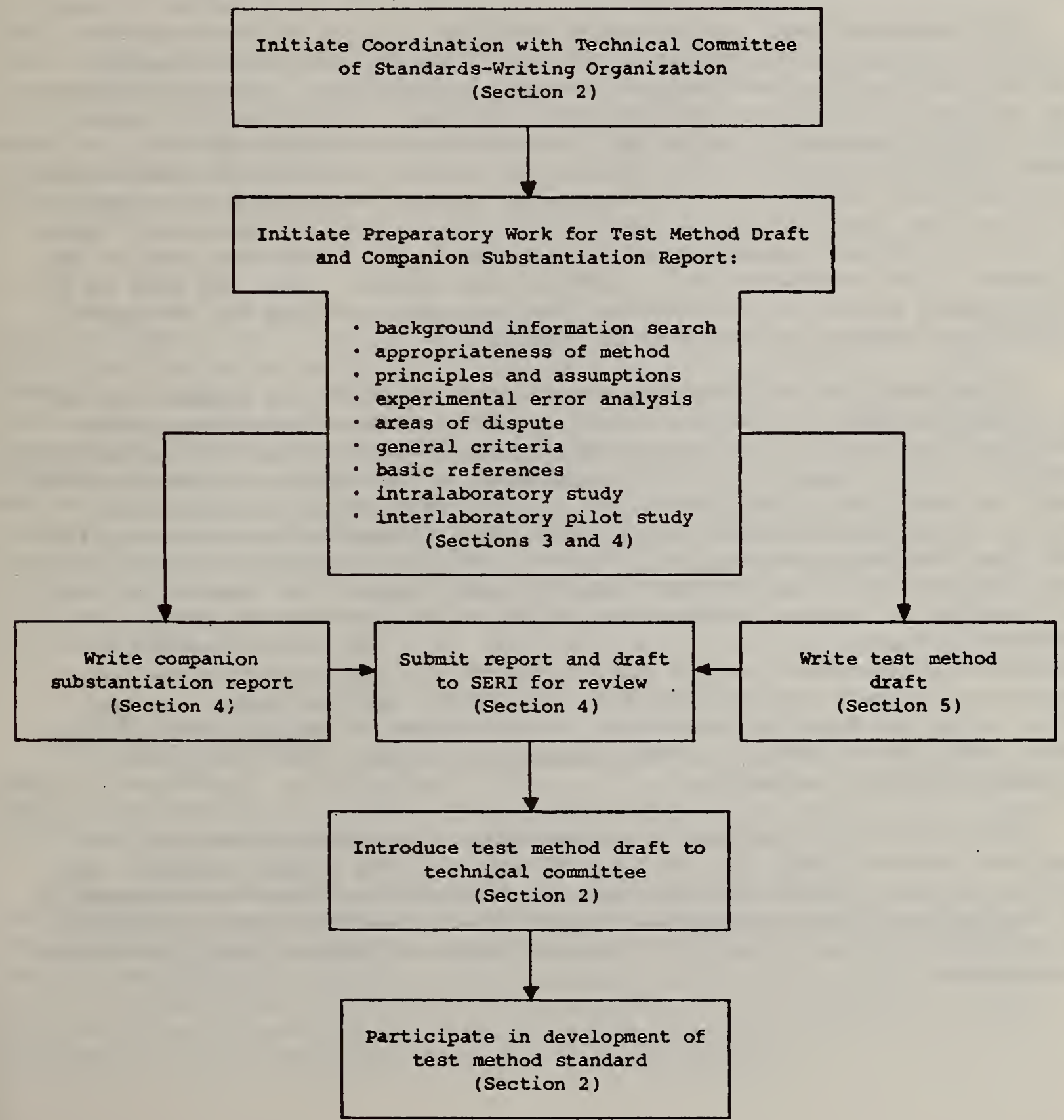




\section{INTRODUCTION OF A TEST METHOD DRAFT \\ TO A STANDARDS-WRITING COMMITTEE - GENERAL CONSIDERATIONS}

The effectiveness of standards developed for PV systems depends on their acceptance and employment in the marketplace. These in turn depend on how well they satisfy perceived needs and to what degree all interested parties feel they have had a chance to participate in their development. Although the use of a standard is voluntary in principle, standards developed by the voluntary consensus process are frequently cited by federal, state, and local governments and they may find use in legally binding codes and regulations. This eventuality makes it essential to document carefully the development of the standard including the preparation of the initial drafts which will serve as the base on which the completed standard is built.

The background work in developing the initial draft of a test method should be designed to facilitate its eventual development into a standard test method by a consensus standards-writing organization. A clear distinction must be drawn between the development of the initial draft of a test method and the process by which the final standard is adopted by the standards-writing organization. The former involves the careful translation of a measurement technique into a precisely written description of a test method and may involve significant experimental work at the laboratory level. The latter involves the consensus process whereby all interested parties participate in the development of a standard test method. Thus, the work on the initial draft should be considered as staff support work for the technical committee to which the draft will be submitted.

It is important that adequate coordination be developed between the organization preparing the initial draft and the technical conmittee. This should be initiated as soon as possible by the preparing organization for two reasons: (1) to insure an effective response by the technical comittee as a result of their early involvement and (2) to avoid unfair discrimination against any product or technology by allowing the opportunity for timely inputs from interested parties (as discussed in sec. 3.3). The coordination with the technical committee may take different forms: for example, it may only involve an initial introduction of the project and the submission of subsequent progress reports to the committee, or it may involve having a representative become an active participant on the committee from the outset. The latter approach will generally be far superior to the former. In any event, after the draft is introduced, a representative should attend meetings of the committee to assist in the process of developing the draft into a consensus standards document.

The selection of appropriate standards-writing organizations for proposed test method drafts and the identification of the target technical committees of those organizations are expected to be made by mutual agreement of the standards-writing organizations represented at meetings of the subcomittee on Phutovoltaics of the ANSI Steering Committee on Solar Energy Standards Development. 


\section{EFFECTIVENESS CRITERIA FOR TEST METHOD STANDARDS}

The organization preparing the initial test method draft should evaluate the draft against the following three general criteria for effective voluntary consensus standards. This should be done both as the draft is being planned and later after it is completed, prior to its introduction to the standards committee. The draft must pass these tests if the standard is to be expected to meet with acceptance by the PV community.

\subsection{Practicality and Economic Feasibility}

The first criterion is that the test method be practical and economically feasible to use. This requires that due consideration be given to the cost of the necessary equipment and facilities, to the time to conduct the test, and to the demands on the skills of the operator performing the test. A related requirement is that the levels of precision and accuracy of the test method be matched to the needs of the PV community. To exceed these needs will needlessly raise the cost and complexity of the test; to fall short of them will make the test method unacceptable as a means of deciding marketplace questions.

\subsection{Lack of Impedance to New Development}

The second criterion is that the test method in no way impede technological development and marketing of new and innovative PV devices and systems. This objective can be achieved in large part by using performance criteria instead of relying on prescriptive specifications. For example, in specifying the apparatus required for a test, if its capability of making a given measurement is the concern, the capability in question should be specified without restrictions as to how the measurement is to be accomplished, unless the way in which the measurement is made impacts the overall results to a significant degree. The specification of capability should thus include the necessary range, precision, accuracy, etc. As a specific example, the use of a temperature sensor with a specified accuracy or sensitivity over a specified temperature range should be required rather than the use of a given type of thermocouple.

\subsection{Avoidance of Unfair Discrimination}

The third criterion is that the test method avoid unfair discrimination against one product or technology in favor of another. This can be achieved for the most part by carefully defining the applicability of the test method and through the development of parallel options in the methods.

The problem of unfair discrimination of a test method against a particular product because of technical difficulties in applying the test largely can be avoided by involving as many interested manufacturers as possible in the test method review process. This procedure is, in fact, one of the principal functions of the standards-writing committee. The importance of avoiding this unfair discrimination is sufficiently important that it should be considered in the first stages of test method development. 


\section{PREPARATORY WORK FOR WRITING AND INTRODUCING A TEST METHOD}

As a useful framework for the preparation of a test method draft, and as a way of testing and demonstrating the validity of the method itself, a number of steps are proposed to the preparer of a draft and are described in subsections 4.1 through 4.9. Following these steps will help ensure that the test method and the draft rest on firm technical grounds and that the method is practical and useful. It will also provide the supporting information that should be used when the draft is introduced to the technical committee of the standards-writing organization. This information should be documented in a companion report to the draft which is to be prepared and submitted with the draft to the technical committee, after review by SERI. The report will serve, additionally, as a useful reference document for the technical committee as it proceeds in the consensus process to develop the initial draft into a standard.

All of the steps listed below need not be followed to develop a satisfactory initial draft. Some may not even be appropriate to a given test method. Nevertheless, it is emphasized that these steps are designed to facilitate and accelerate the development of the initial test method draft to a consensus standard. This is accomplished by providing the substantiation* of the test method that can be used to answer the questions that would be expected to be asked by the technical committee and others involved in the consensus process.

\section{1 Background Information Search}

Collect sufficient background material on the measurement method to ensure that any information relevant to its development into a test method draft is at hand. This may be accomplished with the aid of personal contacts with authorities in the field and by a search of the literature. The search should seek all reports of background research directly applicable to the method, as well as all reported experience in using the method. The scope of the search should include both government reports and the open technical literature. A list of some available data bases that should be considered is provided in table 2 .

\subsection{Appropriateness of Method}

Prepare a background statement about the proposed test method describing its appropriateness for making the required measurement. Describe any competing measurement methods and justify why those methods are less appropriate for the desired measurement. Reference should be made to any closely related test methods that have already been adopted as standards. Reference [7] may be helpful in the search for such methods. As new test methods are developed for photovoltaics, the ANSI Steering Committee on Solar Energy Standards Development should be consulted for an up-to-date list of test methods. If such clostly related standards do exist, the difference between the published standard and the proposed test method should be discussed with emphasis on scope and applicability. The conditions under which the proposed method may

\footnotetext{
* Some technical committees may refer to this substantiation as the

"rationale" for the candidate standard.
} 
Table 2 - Data Bases and Availability for Computer Searches of PV Test Methors

$\underline{\text { Code }}$

NTIS

National Technical Information Servicet includes access to almost all U.S. Government reports (availability B, L,S).

RECON Department of Energy code which includes some reports not accessed through the NTIS search (availability: E).

COMPENDEX

Access to the worldwide engineering and technological literature (availability: L, S).

CA/SEARCH Access to the worldwide literature in chemistry and chemical engineering (availability: $B, L, S)$.

SEIDB

Solar Energy Information Data Bank provides comprehensive access to the literature including patents (availability: SERI).

STAR

Scientific and Technical Aeroscope Reports: NASA sponsored reports (availability: NASA).

INSPEC

Worldwide coverage of the literature in physics, electrotechnology, computer and control engineering. A British data base (availability: B,L,S).

INSPEC A Physics abstracts.

INSPEC B Electrical and electronic abstracts.

INSPEC $C$ Computer and control abstracts.

\section{Availability: *}

B Bibliographic Retrieval Services, Inc.

Building 702

Corporation Park

Scotia, NY 12302

(518) $374-5011$

I Lockheed Information systems

Code 5020/201

3251 Hanover street

Palo Alto, CA 94304

(800) 227-1960

$\mathbf{E}$ Department of Energy

Director, office of Technical Information

Washington, DC 20545

(301) 353-4357

S Systems Development Corporation Search Service

2500 Colorado Avenue

Santa Monica, CA 90406

(213) 829-9463

N National Technical Information Service

5285 Port Royal Road

Springfield, VA 22161

(703) 557-4642

NASA National Aeronautics and Space Administration Office of Technology Utilization

Scientific and Technical Information Division

600 Independence Avenue, S.W.

Washington, DC 20546

(202) $755-2210$

SERI Solar Energy Information Center

Computerized Databases

Solar Energy Research Institute

1536 Cole Boulevard

Golden, $\mathrm{CO} 80401$

(303) 231-1960

†National Technical Information Service, Springfield, VA 22161, Tel: (703) 557-4780.

*Access to these sources is also provided by many large public libraries and universities. 
be used instead of the published one should also be discussed. If the proposed test method complements an existing standard, the conditions for which each applies and the benefit to be gained from the proposed method should be identified.

\subsection{Principles and Assumptions}

Specify any fundamental scientific or engineering principles on which the test method is based. State any fundamental assumptions on which the method is based, and indicate how the validity of these assumptions can be checked. Also, include any precautions in interpreting the results of the test which relate to the assumptions made.

\subsection{Experimental Error Analysis}

Make an analysis of how various aspects of the measurement method may introduce errors in the value of the quantity to be determined by the method; aspects such as measurement procedure, condition and type of test specimen, apparatus, and laboratory conditions should be considered. It is useful in the formative stages of a measurement method to predict the anticipated precision and accuracy of the method, based on elementary laboratory error analysis. Such an analysis may be able to suggest timely modifications in the procedure or other aspects of the method that will contribute to an improved mea surement.

The analysis should include an estimate, either from actual trials or by a theoretical investigation, of the magnitude of error that might reasonably be expected in the measurement of each parameter. It should also determine how measurement results may be affected by variations in critical instrumentation, specimen type and preparation, ambient conditions, and operator performance. The effect of all these possible sources for measurement error on the quantity to be determined by the test method should be calculated by accepted propagation of error techniques [8].

If the magnitude of the calculated error warrants, an investigation should be conducted to find alternative procedures or approaches which will make the method less sensitive to measurement variables. If other options become evident, use error analyses to aid in the selection of the optimum procedure.

The results of error analyses and the conclusions derived therefrom should be included in the companion report to the preliminary draft test method.

\subsection{Areas of Dispute}

Identiry any areas of likely dispute over the specifications or procedures of the test method. Describe the reasons for any dispute, indicating the pros and cons of any likely alternatives. 


\subsection{General Criteria}

Demonstrate that the draft test method meets the general criteria in section 3 by addressing the following issues where appropriate:

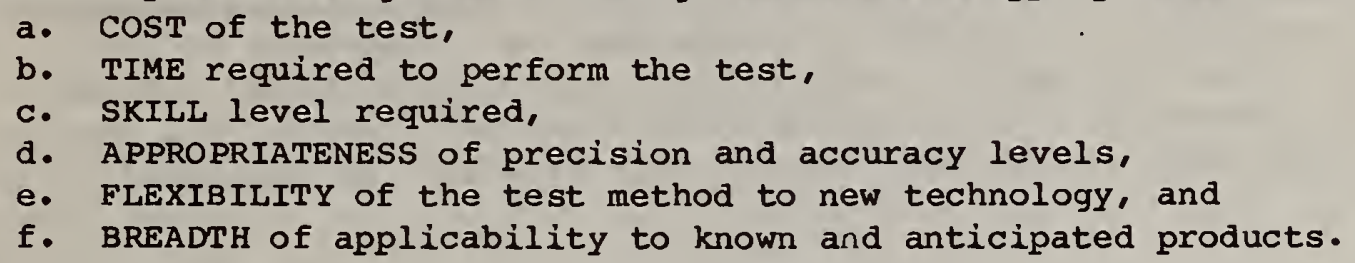

\subsection{Basic References}

Prepare a list of those documents that form the basic references for the test method and which should be of value to the reviewing standards committee and to a potential user of the method. Each entry should be accompanied by a statement explaining why the paper should be of interest. The test method draft should, however, be self-contained in that the user should not be required to consult the references for a successful application of the test. References are used to provide additional information such as the origin of a functional relationship expressed in an equation.

\section{8 Intralaboratory Study}

Evaluate the instructions for performing the test method for completeness and clarity by observing an operator following these instructions who is uninitiated in the method yet experienced in the general measurements required. Where problems are apparent in following the instructions, the instructions must be appropriately modified. The adequacy of the instructions and the method itself may be tested by having several operators perform the test method on the same or similar test specimens and noting the variation in test results.

\subsection{Interlaboratory Pilot Study}

When there exists little experience with the test method or when a high degree of precision is required, it may be useful to conduct an interlaboratory pilot study after the initial draft has been prepared. Where a technical committee of a standards writing organization has been identified to have an interest in the initial test method draft being written and a pilot study is justified, the pilot study should be coordinated by that committee, if practical. The pilot study should involve only two or three laboratories in addition to the one developing the test. The interlaboratory pilot study is intended to be a less formal and less rigorous interlaboratory experiment than the committee may wish to conduct later as a final evaluation of the test method. The purposes of a pilot study are usually threefold:

a. To assess the general technical feasibility of the test method.

b. To identify any major technical problems that arise in applying the test.

c. To obtain a preliminary indication of the precision that might be expected of the test method and to identify those measurement parameters which are the principal contributors to error in the method. 


\section{PROCEDURE FOR THE PREPARATION OF A PRELIMINARY TEST METHOD DRAFT}

The steps listed below should be followed in the preparation of initial test method drafts intended for introduction to standards-writing organizations. The procedure is intended to standardize the preparation of such drafts so that they will have an acceptable level of completeness and uniformity. The completion of each of the steps below will result in a part or a section of the test method draft according to the headings indicated:

\subsection{Title}

Select a title that is fully descriptive of the particular test method. Consult other related published standard test methods to determine that no ambiguity exists. It will be left to the technical committee to develop a title that may be more concise and readily indexable.

\subsection{Scope}

Specify the scope of the test method. Include a statement of the purpose of the method and the range of application. Make sure the scope statement provides the reader with enough information to determine whether or not the test method meets his or her measurement requirements. To avoid possible misinterpretation, specify explicitly those conditions for which the method does not apply as well as for those for which it does. For example, specify clearly the solar cell types for which a cell test method is intended as well as those for which it is not suitable.

The applicability of the test method to various devices or systems should be as broad as possible to extend the benefits of standardization to as large a class of items as is feasible. Since the absence of a standard test method for the performance of a given product can inhibit its commercial viability, no product should be excluded except for sound technical reasons. On the other hand, only that range of products for which the method can be tested by interlaboratory comparison should be included.

\subsection{Use}

State the context in which the test method being proposed may be used. For example, is it appropriate for use in research and development, in quality control by the manufacturer, in specification checking by the consumer, or in the satisfaction of regulation or code requirements? If there are any reasons why the proposed test method would not be satisfactory in a given context, identify these limitations.

\subsection{Significance}

State the technical importance of the test method and its overall significance to the industry or discipline involved. 


\subsection{Summary of Method}

Describe the method briefly, including any names commonly used to refer to it. Outline enough of the procedure that the reader can determine the basic method without having to go through the detailed procedure.

\subsection{Definition, Terminology, and Symbols}

Collect definitions, terminology, and symbols used in the method. In any field, technical terms and jargon inevitably become part of the working vocabulary. Make sure that this collection is sufficiently complete (together with terminology from other documents which are referenced as being essential for carrying out the method) that a technically trained person outside the field can understand all the terms used in the draft test method. Use standard definitions, terminology, and symbols when available. Ensure that all definitions are consistent with those already defined in published standards.

\subsection{Apparatus and Materials}

Describe the test equipment and expendable supplies required by the test method. Specify any levels of performance that are needed in the test equipment and supplies for a satisfactory execution of the test. For example, if a current meter requires at least one-percent accuracy, it must be so specified rather than indicating simply that an accurate meter is needed. The range of values over which an instrument must have a certain accuracy should be specified. However, it is important not to require greater accuracy than is actually needed. In general, one should avoid prescriptive specifications that would tie the test to a particular piece of apparatus. Having provided a generic description of the required capabilities, it may be useful, however, to indicate that a given kind of apparatus has proven to be satisfactory for the prescribed use. This guidance may facilitate the selection of apparatus for the test. If such a statement is made, the policy of the organization for whom the initial draft is intended should be consulted for its endorsement disclaimer.

\subsection{Safety}

Describe any safety precautions that must be followed by personnel conducting the test.

\subsection{Statistical Sampling and Measurement}

Recommend any statistical sampling techniques required by the test $[9,10]$. If, for example, the test method is used for quality control in a manufacturing process, suggest such important quantities as the percentage of production units to be selected for testing and the manner of selection. It is possible that such a sampling plan will depend on data from actual production experience which may not be available at this stage. When such data become available, it may be necessary to modify the sampling techniques. 


\subsection{Procedure}

Write out the detailed step-by-step procedure to be followed in logical order in the conduct of the test method.

Consider the following points and include material responding to those that are appropriate:

\subsubsection{Error}

Identify those parts of the procedure which are particularly likely to introduce measurement error. (Provide in notes suggestions for avoiding such errors.)

\subsubsection{Checks}

Include any checks that can be made in the course of the measurement which will help to verify the accuracy or precision of intermediate steps.

\subsubsection{Illustrations}

Provide illustrations (i.e., structural diagrams, etc.) when pictorial representation will aid understanding. (Caution: use the same labels in text and figures.)

\subsubsection{Experience}

As a result of experience with a given test method, it may be discovered that special care must be exercised in certain steps. Include the benefit of this experience in the written procedure of the method whenever possible, or incorporate suggestions (i.e., nonessential instructions) in notes.

\subsubsection{Statistical Requirements}

Incorporate in the procedure any statistical requirements that are imposed by the test method itself. For example, where a measured parameter is subject to random fluctuations, it may be necessary to call for an average of several measurements to obtain the needed accuracy. Specify in the procedure how many measurements are to be made and how the data are to be recorded and tested.

\subsubsection{Repeated Measurements}

Include in the procedure, as required, instructions for repeated measurements on the same specimen over an extended period of time. Specify an appsopriate time interval between tests when such a need exists.

\subsubsection{Interferences}

Describe in notes (or, optionally, in a separate section) any potential interferences with the test method that may be anticipated. Interfer- 
ences are those factors which may affect the precision or reproducibility of the test in ways that are difficult or impractical to quantify. An example of an interference is foreground surface reflection in outdoor PV device measurements.

\subsubsection{Alternatives}

There may be cases where there are several alternative procedures that involve a balancing of factors, all of which are not attainable in one procedure. Where these alternatives are technically acceptable and the test is to be used as part of a buyer-seller transaction, it may be desirable to allow this choice to be "subject to agreement by the parties of the test." If this choice is allowed, describe the trade-offs of the factors in each alternative so that buyer and seller may mutually be able to select the best procedure for the situation at hand.

5.10 .9 SI Units

Use SI units [11] throughout. One of the major near-term markets expected for PV system is the export market. It is very important therefore that quantities in PV test methods be expressed in the international system of units even though customary engineering units are also indicated.

\subsection{Calculations and Reporting}

Specify how any calculations are to be made and how the test results should be reported in a step-by-step procedure. For complex tests provide a standard report form as part of a draft.

\subsection{List of References}

Prepare a list of those references referred to in the text of the initial test method draft.

\subsection{Table of Contents}

Include a table of contents for those drafts where length and complexity warrant. 


\section{Acknowledgment}

The authors would like to acknowledge and thank those who provided helpful comments to earlier drafts which allowed us to make this a more complete report. Special thanks go to J. Franklin Mayo-Wells for his particularly knowledgeable and diligent reviews.

\section{References}

1. Schafft, H. A., Standards for Photovoltaic Energy Conversion Systems, NBSIR 79-1743. [Available froin the National Technical Information Service, Springfield, VA 22161, using order number PB 296 274, Tel: (703) $557-4780]$

2. Form and Style for ASTM Standards, Fourth Edition (June 1976). [Available from ASTM, 1916 Race street, Philadelphia, PA 19103, Tel: (215) 299-5400]

3. IEEE Standards Manual and Style for IEEE Standards (March 1978 ). [Available from the IEEE Headquarters, 345 East 47 th street, New York, NY 10017, Tel: (212) 644-7960]

4. Style Manual for Preparation of American National Standards (August 1972). [Available from the American National Standards Institute, 1430 Broadway, New York, NY 10018, Tel: (212) 354-3300]

5. Method of Development, Revision, and Implementation of Underwriters Laboratories Standards for Safety (1978). [Available from Underwriters Laboratories, Inc., 207 East ohio Street, Chicago, IL 60611, Tel: (312) 642-6969]

6. Style Manual for EIA Publications (March 1974). [Available from EIA, 2001 Eye street, N.W., Washington, DC. 20006, Tel: (202) 457-4900]

7. An Index of U.S. Voluntary Engineering Standards, W. J. Slattery, Ed., NBS Special Publication 329 (March 1971). [Available from the National Technical Information Service, U.S. Department of Commerce, Springfield, VA 22161, using order number COM 71-50172, Tel: (703) 557-4780]

An Index of U.S. Voluntary Engineering Standards, W. J. Slattery, Ed., NBS Special publication 329, Supplement 1 (December 1972). [Available from the National Technical Information Service, U.S. Department of Commerce, Springfield, VA 22161, using order number COM 73-50679, Tel: (703) 557-4780, also available as updated microforms]

An Index of U.S. Voluntary Engineering Standards, W. J. Slattery, Ed., NBS Special publication 329, Supplement 2 (May 1975). [Available from the Superintendent of Documents, U.S. Government Printing office, Nashington, DC 20402, using stock number 003-003-01362-5, Tel: (202) $783-3238]$

N.B. These indexes are being consolidated into one updated document which is expected to be available by fall 1980. 
8. Beers, Y., Introduction to the Theory of Error (Addison-Wesley Publishing Co., Reading, Massachusetts, 1957).

9. Precision Measurement and Calibration, Statistical Concepts and Procedures, H. H. Ku, Ed., Volume 1, NBS Special Publication 300 (February 1969). [Available from Superintendent of Docurnents, U. S. Government Printing Office, Washington, DC 20402]

10. Mandel, J.. The Statistical Analysis of Experimental Error (Interscience, wiley, New York, 1964). [A basic reference volume for error analysis]

11. ASTM/IEEE Standard Metric Practice, ASTM E380-75 or IEEE Std. 268-1979. [Available from the Institute of slectrical and Electronics Engineers, Inc., 345 East 47 Street, New York, NY 10017] 



\begin{tabular}{|c|c|c|c|}
\hline $\begin{array}{c}\text { U.S. DEPT. OF COMM. } \\
\text { BIBLIOGRAPHIC DATA } \\
\text { SHEET }\end{array}$ & $\begin{array}{c}\text { 1. PUBLICATION OR REPORT NO. } \\
\text { NBSIR } 80-2060\end{array}$ \\
\hline
\end{tabular}

4. TITLE AND SUBTITLE

Drafting Test Methods for Photovoltaic Systems

7. AUTHOR(S)

William F. Lankford and Harry A. Schafft

9. PERFORMING ORGANIZATION NAME AND ADDRESS

NATIONAL BUREAU OF STANDARDS

DEPARTMENT OF COMMERCE

WASHINGTON, DC 20234

12. SPONSORING ORGANIZATION NAME AND COMPLETE ADDRESS (stroet, city, state, $z I P$ ) Solar Energy Research Institute Quality Assurance \& Standards Branch Golden, CO 80401
Dept. of Energy

Photovoltaic Systems

Branch

Washington, DC 20545

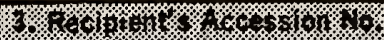

5. Publication Date

June 1980

8. Performing Organ. Report No.

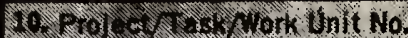

11. Contract/Grant No. SERI subcontract XP-9-8028-1; DOE Con. No. EG-77-C-1-4042

13. Type of Report \& Period Covered

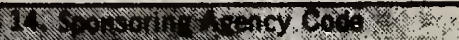

15. SUPPLEMENTARY NOTES

Document describes a computer program; SF-185, FIPS Software Summary, is attached.

16. ABSTRACT (A 200-word or less factual summary of most significant information. If document includes a significant bibliography or literature survey, mention it heso.)

General guidance and a step-by-step procedure are provided as aids in the development of Initial drafts of test methods for photovoltalc energy components and systems. It is intended that these drafts will be referred to the appropriate technical committees of organizations writing voluntary consensus standards. This approach is designed to facilitate the expeditious development of consensus test method standards for photovoltaic systems. The procedure is therefore designed to be compatible with the requirements of existing standards organizations.

17. KEY WORDS (six to twelve ontries; alphabetical order; capltalize only the first letter of the first key word unless a proper name; soparated by oemicolons)

Consensus standards; measurement technology; photovoltalc energy conversion; photovoltalcs; solar cells; test method preparation.

\begin{tabular}{|l|c|}
\hline $\begin{array}{l}\text { 19. SECURITY CLASS } \\
\text { (THIS REPORT) } \\
\text { UNCLASSIFIED }\end{array}$ & $\begin{array}{l}\text { 21. NO. OF } \\
\text { PRINTED PAGES }\end{array}$ \\
\hline $\begin{array}{l}\text { 20. SECURITY CLASS } \\
\text { (THIS PAGE) } \\
\text { UNCLASSIFIED }\end{array}$ & $\begin{array}{l}\text { 22. Price } \\
\$ 5.00\end{array}$ \\
\hline
\end{tabular}

Order From Sup. of Doc., U.S. Government Printing Office, Washington, DC 20402, SD Stock No. SNO03-003-

X Order From National Technical Information Service (NTIS), Springfield, VA. 22161 


